\title{
Can Nurses Be Employed in 12-Hour Shift Systems?
}

\author{
Teresa Makowiec-Dąbrowska \\ Patrycja Krawczyk-Adamus \\ Elżbieta Sprusińska \\ Zbigniew W. Jóźwiak
}

\section{Department of Work Physiology and Ergonomics, Nofer Institute of Occupational Medicine, Łódź, Poland}

\begin{abstract}
Nurses are often obliged to work in a 12-hr shift work system. We have decided to check whether such a working system constitutes an excessive load for nurses. On the basis of a questionnaire survey among nurses working in an 8-hr daytime shift system (169 nurses) and in a 12-hr shift (536 nurses), the amount of physical workload, work stress, and after-work activities were compared. Data analysis has shown that a 12-hr shift system is characterized by less significant physical workload but greater mental load. The nurses working in a 2-shift system were more tired after work, but they could spend more time on leisure activities and do housework. The data suggest that there are no significant contraindications for nurses to work in a 2-shift system.
\end{abstract}

shift work 12-hr work system physical workload work stress

\section{INTRODUCTION}

People who start work for the health care are usually in no doubt that they will have to work at different times during the $24 \mathrm{hrs}$. Work organization may be different in various healthcare units because of different patients' needs and the different character of duties. In hospitals, medical care should be provided throughout the 24 hrs; the majority of staff, however, work

Correspondence and requests for reprints should be sent to Teresa MakowiecDąbrowska, The Nofer Institute of Occupational Medicine, Department of Work Physiology and Ergonomics, ul. Św. Teresy od Dzieciątka Jezus 8, P.O. Box 199, 90-950 Łódź, Poland. E-mail: <impx@porta.imp.lodz.pl>. 
from early morning until early afternoon. Late afternoon and night hours are times of work for only a small group of the staff. Thus there are groups of employees working only on the day shift, sometimes with overtime, or in a shift system involving night work.

One of the most common ways of employing nurses is a two-shift system, which involves a 12-hr duty followed by at least 24-hrs of leisure time. Nurses also work 8-hr shifts, in the daytime only, or as part of a three-shift system (Lenartowicz \& Gawel, 1998). The system of prolonged 12-hr shifts is favored, particularly because of accumulated working periods. Thus, to achieve the monthly number of working hours, only 14 working periods are required by the hospitals, whereas with the 8-hr working day, there have to be 21 such periods. At the same time, it is possible to accumulate leisure time, which not only facilitates family life but also enables the avoidance of stressful work for a longer period of time (Makowiec-Dąbrowska, 1991; Rosner, 1990).

However, although a system of 12-hr shifts might be advantageous administratively, studies carried out on shift workers employed in such a system indicate that problems arise (Urgovics \& Wright, 1990). Some data from nurses suggest that excessive fatigue arises caused by an extension of work time over the usual 8-hr working day (Knauth, 1993), as well as performance decrement (Todd, Reid, \& Robinson, 1989). It is recommended that nurses work a 12-hr shift work system only exceptionally, for example, during weekends, as after a 10-hr working period fatigue increment together with motivation and performance decrement are usually noted (Easki, 1986).

A nurse's job entails a significant workload. This is due to the physical effort connected with performing everyday duties, such as lifting or moving heavy objects (patients), and to activities that are carried out in a constrained position. There is also a significant mental stress resulting from the necessity of continuous concentration and quick responses to changes in the patients' condition, as well as that due to emotional relationships with patients.

In the ergonomic guidelines concerning shift work organization (Knauth, 1997), it was recommended that the duration of work on any shift should be adapted to its nature. Therefore, we decided to check whether the work of hospital nurses in a 12-hr shift system produced an excessive load for them. The opportunity for such an evaluation came from material collected during a comprehensive questionnaire survey of workload and working conditions in nurses (carried out in the years 1997-98 in a random trial of 1,500 nurses employed at different health care units in Łódź, Poland, and its districts). 
These results were analyzed by comparing physical workload and work stress, as well as such reactions to work as mood states and fatigue, among nurses employed in a 12-hr shift system with those employed only on a daytime shift lasting 8 hrs.

\section{MATERIAL AND METHODS}

Nurses were selected who had worked at a hospital for at least one year (in the daytime, on $8-\mathrm{hr}$, or $12 \mathrm{hr}$ shifts), and who did not perform any managerial functions. These criteria were met by 698 nurses. They were employed at Intensive Care Units (ICU), Pediatric Departments (PD), Surgical Departments and other operational wards (SD), Internal Diseases and other non-operational wards (ID), and Admissions and Diagnostic Laboratories (A and DL).

The following parameters were used to determine physical workload:

- The amount of energy expenditure, determined by Lehmann's method, based on observation of activities being performed and their duration (Lehmann, 1966). The energy expenditure during work was presented as kilocalories per hour. According to regulations implemented in Poland, the physical workload can be light (when energy expenditure is below 90 $\mathrm{kcal} / \mathrm{hr})$, moderate $(90-125 \mathrm{kcal} / \mathrm{hr})$, hard $(125-150 \mathrm{kcal} / \mathrm{hr})$, or very hard (over $150 \mathrm{kcal} / \mathrm{hr}$ ).

- The indices of moving, lifting, and carrying objects, calculated by multiplying the number of kilograms moved, lifted, or carried by the number of times an activity is performed, divided by the duration, in minutes, of performing this activity.

- The number of minutes per hour spent in constrained, uncomfortable positions, for example, bending, twisting, crouching, standing on tiptoes.

Work stress was determined according to job demands-the job control model of Karasek (1979). The job demands indicator was constructed to measure psychological stressors affecting work, work pace, overload, and the presence of conflicting demands ( 7 items). Job control reflects both skill and creativity required to perform a job (skill discretion), as well as the freedom to make decisions related to work (decision authority), and personal schedule freedom (13 items). Evaluation of the demands and control was carried out by the same participants using a 1-5 scale for each item. 
The level of global stress was assessed by questionnaire. This questionnaire measured the extent to which one considers one's own life problems as stressful. The participants determined the extent to which they considered their own life as unpredictable, beyond personal control, and excessively affected by others (Cohen, Kamarck, \& Mermelstein, 1983). The questionnaire contains 14 items evaluated on a $0-4$ scale.

The level of fatigue after work on the day preceding the survey was assessed subjectively by defining it as a percentage of the highest fatigue experienced so far at work.

Apart from fatigue, the participants defined their mood state according to the Profile of Mood States questionnaire (Dudek \& Koniarek, 1987). It contains 65 descriptions of various feelings and moods, divided into the following groups: anger-hostility (12 items), fatigue-inertia ( 7 items), depression-dejection (15 items), vigor-activity (8 items), embarrassment ( 7 items with one negative value), friendliness ( 7 items), and tension-anxiety (9 items with one negative value). The occurrence of each symptom was evaluated using a 1-5 scale.

The participants also defined the total number of hours taken up by housework and by the hardest physical work at home. They also recorded the number of hours of leisure-time physical activity (walking, jogging, cycling, aerobic exercise, etc.) during the week. The amount of sleep of the participants was recorded as

- the number of sleep hours during a working day (average from 3 working days),

- the number of sleep hours during a typical day of leisure.

After collecting data, significant age differences between groups of nurses working in the one- and two-shift systems were found. Therefore, a statistical analysis comparing the two types of work system was carried out, excluding the effects of age.

\section{RESULTS}

The age of the nurses under study ranged from 20 to 60 . The nurses working on the 8-hr daytime shifts were older than those working in the two-shift system. The average duration of performing nursing duties was $14.9( \pm 9.4)$ years but, whereas the average number of years working the present shift work system was $9.9( \pm 7.6)$ years for the daytime shift, it was $8.8( \pm 5.6)$ years for those working the two-shift system (Table 1). 


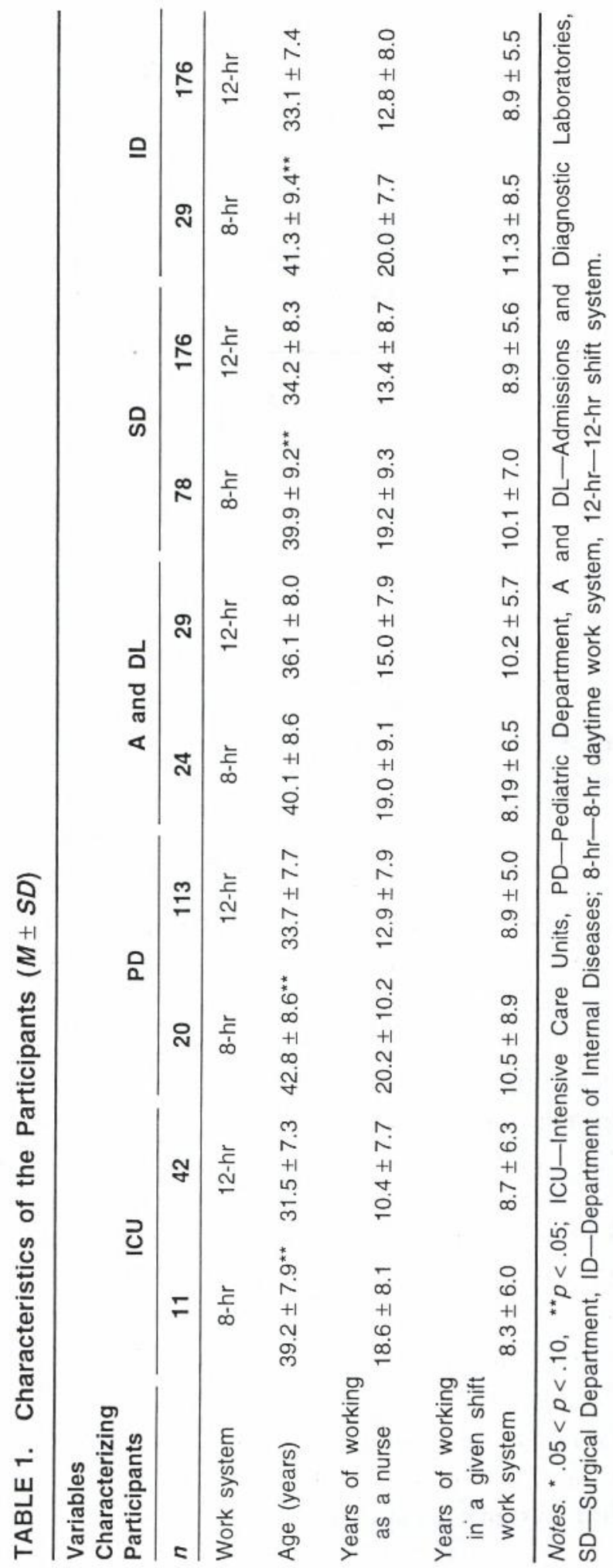


For most of the nurses, the physical workload was moderate, energy expenditure being within the range $90-125 \mathrm{kcal} / \mathrm{hr}$. Most of the cases where the workload was high applied to nurses employed in A and DL. Among them, over $11 \%$ performed hard work $(>125 \mathrm{kcal} / \mathrm{hr})$ and over $2.5 \%$ very hard work (>150 kcal/hr; Table 2).

TABLE 2. Distribution of Energy Expenditure Among Nurses Working in the Five Departments (\%)

\begin{tabular}{lccccc}
\hline $\begin{array}{l}\text { Energy Expenditure } \\
\text { (kcal/hr) }\end{array}$ & ICU & PD & A and DL & SD & ID \\
\hline$<90$ & 21.79 & 35.90 & 51.95 & 23.00 & 31.00 \\
$90-125$ & 66.67 & 55.13 & 33.71 & 65.00 & 58.08 \\
$125-150$ & 10.26 & 8.33 & 11.69 & 10.33 & 9.61 \\
$>150$ & 1.28 & 0.64 & 2.60 & 1.67 & 1.33 \\
\hline
\end{tabular}

Notes. ICU-Intensive Care Units, PD-Pediatric Department, A and DL-Admissions and Diagnostic Laboratories, SD-Surgical Department, ID-Department of Internal Diseases.

In each department, statistically significant differences were obtained between the workload indices during the 12- and 8-hr shifts for the two groups of nurses (Table 3). Moreover, statistically significant differences were noted between the two systems in the nurses' sleep duration, hours of housework, and leisure-time physical activity (Table 4).

Physical workload was greater during 8-hr daytime shifts in ICU, where nurses moved objects more, and more often, and also spent more time (per hour of work) in constrained positions. In SD and ID, too, the energy expenditure per hour of work was higher for nurses working the one-shift system.

The two shift systems differed also in the level of work stress. Nurses from ICU and PD working in the 8-hr one-shift system had slightly higher levels of job demands, and they also had higher job control. Other nurses, working in the same shift system in A and DL, SD, and ID were characterized by a higher level of job control but slightly lower levels of work demand (Table 3). Generally, the level of job control among nurses working the 8-hr daytime shifts was higher than among nurses working in the 12-hr, two-shift system; accordingly, their work stress was lower. 


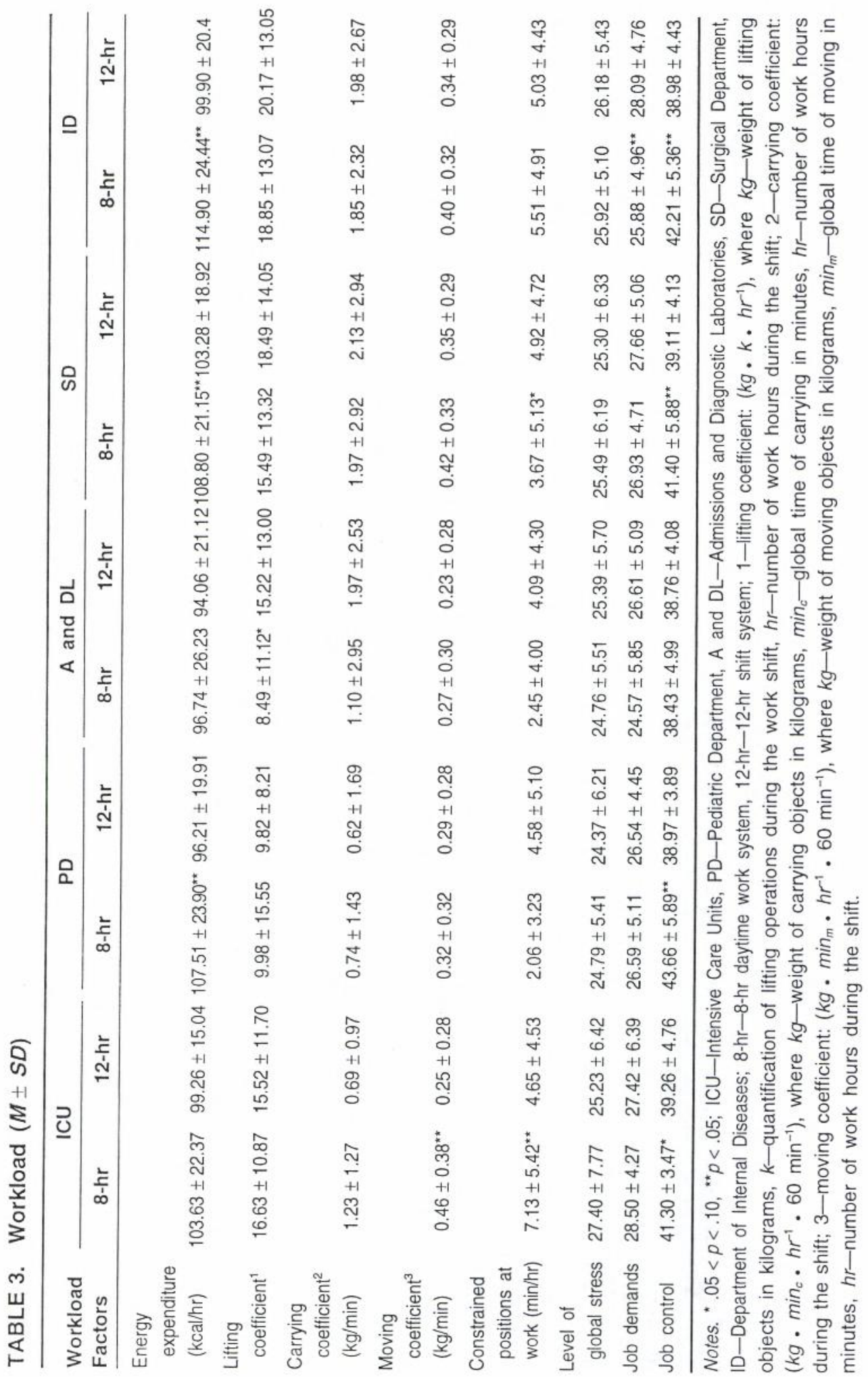




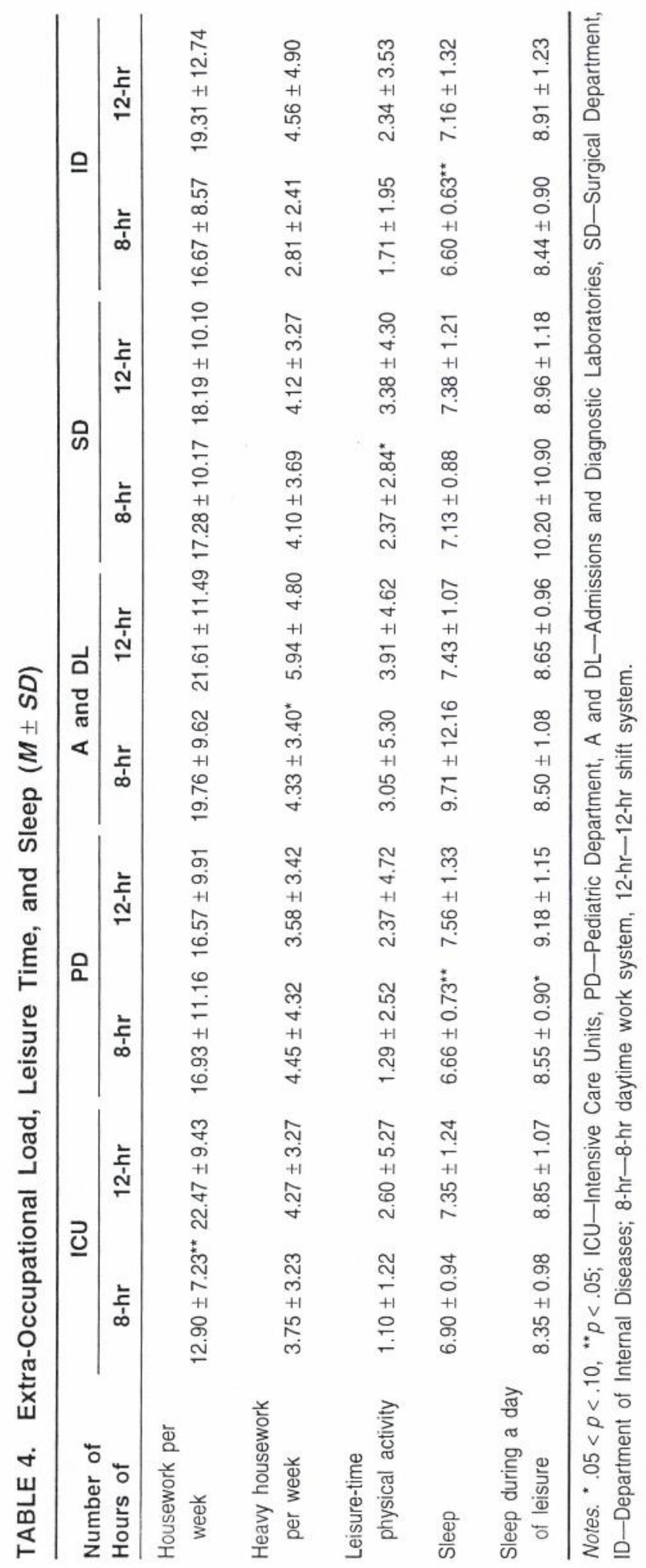




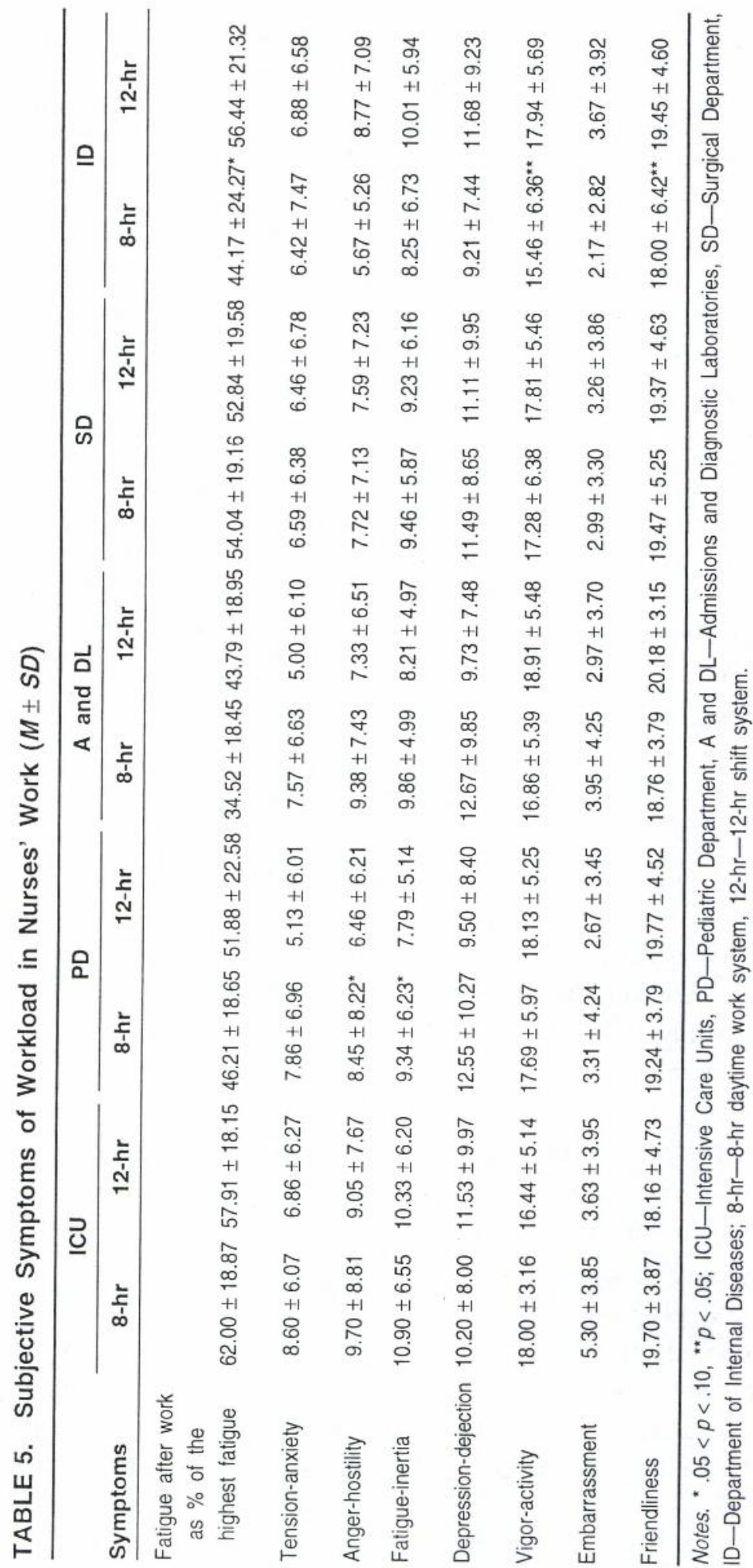


When analyzing extra-occupational workload, it was noted that differences between nurses working $8-\mathrm{hr}$ daytime shifts and 12-hr shifts were rarely significant. The exception was the nurses from ICU working a 12-hr shift system, who could spare more time for the housework $(p<.05)$ in comparison to the nurses working 8-hr daytime shifts (Table 4).

The response to the workload on the 8-hr daytime shifts was expressed as poorer mood states when compared with the nurses working in the 12-hr shift system (Table 5), namely, greater fatigue and hostility in the nurses working in PD $(.05<p<.10)$ and a lower degree of friendliness (significantly lower only in the case of nurses from ID).

The level of fatigue after work did not differ significantly between the groups of nurses although for nurses from most of the departments (PD, $\mathrm{A}$ and DL, ID), it tended to be higher $(.05<p<.10)$ among those who worked in the 12-hr shift system (Table 5). This group of nurses also slept longer on working days (for PD and ID, $p<.05$ ) and tended to do so on leisure days (for $\mathrm{PD}, .05<p<.10$ ). Moreover, those working on $12 \mathrm{-hr}$ shifts pursued a greater number of leisure-time physical activities-aerobic exercise, jogging, cycling-but this difference was only marginally significant (for nurses working at $\mathrm{SD}, .05<p<.10$; Table 4).

\section{CONCLUSIONS}

The comparison between the two shift systems has revealed several significant differences between them. These differences were connected mainly with physical workload and work stress. The differences in the amount of energy expenditure seemed to favor the two-shift work system. With this system, however, there was a greater level of work stress, a smaller level of job control, and greater job demands. These nurses also reported greater fatigue when compared to those working on the 8-hr shifts. Work in the two-shift (12-hr) system, however, allowed the nurses more spare time to do the housework and to pursue physical activities in their leisure time; also, the nurses could plan and utilize their leisure time better.

We conclude that a lesser physical workload and the lack of significant differences in fatigue levels, as well as the possibility of better utilization of leisure time (at least in the $24 \mathrm{hrs}$ after a $12-\mathrm{hr}$ shift), indicate that there are no general contraindications to this system being worked by nurses. 


\section{REFERENCES}

Cohen, S., Kamarck, T., \& Mermelstein, R. (1983). A global measure of perceived stress. Journal of Health and Social Behavior, 24, 385-396.

Dudek, B., \& Koniarek, J. (1987). Adaptacja testu D.M. McNaira, M.Loora, L.F. Dropplemana Profile of Mood States (POMS) [Adjustment of D.M. McNair's, M.Loor's, L.F. Droppleman's questionnaire Profile of Mood States (POMS)]. Przeglad Psychologiczny, XXX(3), 753-762.

Karasek, R. (1979). Job demands, job decision latitude, and mental strain. Implications for job redesign. Administrative Science Quarterly, 24, 285-308.

Knauth, P. (1993). The design of shift systems. Ergonomics, 36, 15-28.

Knauth, P. (1997). Changing schedules: Shift-work. Chronobiology International, 14, 159-171.

Lehmann, G. (1966). Praktyczna fizjologia pracy [Applied work physiology] (F. Shittek, Trans.). Warsaw, Poland: PZWL. (Original work published 1962, German title Praktische Arbeitphysiologie).

Lenartowicz, H., \& Gawel, G. (1998). Praca zmianowa pilęgniarek. [Shift work of nurses]. In I. Iskra-Golec, G. Costa, S. Folkard, T. Marek, J. Pokorski, \& L. Smith, (Eds), Stres pracy zmianowej. Przyczyny skutki, strategie przeciwdziatania (pp. 199-212). Cracow, Poland: Universitas.

Łaski, Z. (1986). Prawa rządzące intensywnością pracy-Wnioski dla kierowania praca w przedsiębiorstwie [Rights that regulate workload-Conclusions for coordinating work in a company]. Doskonalenie Kadr, 1, 3-5.

Makowiec-Dąbrowska, T. (1991). Social aspects of undertaking shift-work including nightwork of women in Poland. Ergonomia, 14, 131-135. (In Polish).

Rosner, J. (1990). Night-work shift of women. Ergonomia, 13, 219-224. (In Polish).

Todd, C., Reid, N., \& Robinson, G. (1989). The quality of nursing care on wards working eight and twelve hour shifts: A repeated measures study using the MONITOR index of quality of care. International Journal of Nursing Studies, 26, 359-368.

Urgovics, A., \& Wright, J. (1990). 12-hour shifts: Does fatigue undermine ICU nursing judgements. Nursing Management, 21, 64A-G. 